\title{
PAI-1 polymorphisms modulate phenotypes associated with the metabolic syndrome in obese and diabetic Caucasian population
}

\author{
C. Lopes ${ }^{2}$, C. Dina ${ }^{2}$, E. Durand ${ }^{1}$, P. Froguel ${ }^{1,2}$ \\ ${ }^{1}$ CNRS Institute of Biology, Institut Pasteur de Lille, Lille, France \\ ${ }^{2}$ Hammersmith Genome Centre, Imperial College, London, UK
}

\section{Abstract}

Aim/hypothesis. Plasminogen activator inhibitor-1 (PAI-1) is a main regulator of the endogenous fibrinolytic system and modulates the thrombosis progression. We analyzed genetic contributions of PAI-1 mutations to the metabolic syndrome and to its complications.

Methods. PAI-1 promoter and coding sequences were screened for mutations. Genotypes were determined for 1067 unrelated individuals of a French Caucasian cohort, selected for diabetes and obesity. Association between PAI-1 polymorphisms and phenotypes related to metabolic syndrome were statistically studied.

Results. There were five variants identified: two common polymorphisms, $-7654 \mathrm{G} / 5 \mathrm{G}$ and $-844 A>G$, in the promoter, and three new non-synonymous SNPs, Ala15Thr, Val17Ile and Asn195Ile. In obese non-diabetic subjects, the two promoter polymorphisms were associated with higher fasting glucose concentrations ( $p=0.006$ and $p=0.0004$, for $-7654 \mathrm{G} / 5 \mathrm{G}$ and -844 $A>G$, respectively) and insulin ( $p=0.05$ and $p=0.008$, for $-7654 \mathrm{G} / 5 \mathrm{G}$ and $-844 A>G$, respectively). More- over, the $-844 A>G$ SNP was associated with lower triglyceride $(p=0.002)$ and higher HDL cholesterol concentrations $(p=0.02)$ in lean subjects. In addition, the two promoter and Ala15Thr polymorphisms showed a trend towards association with CHD in diabetic subjects $(-765$ 4G/5G: 0.56/0.51, $p=0.05$; $-844 A>G$ : 0.63/0.57, $p=0.02$; Ala15Thr: 0.91/0.88, $p=0.04)$. The SNPs Ala15Thr, located in the PAI-1 signal peptide, and rare the Asn195Ile, located in a $\beta$ sheet structure, could influence conformation of these two structures.

Conclusions/interpretation. Our results support the hypothesis that $P A I-1$ polymorphisms probably interact with known environmental risk factors (chronic hyperglycaemia, obesity, etc.) to induce a more severe insulin-resistant metabolic profile in overweight subjects, and to further increase risk for CHD in diabetic subjects. [Diabetologia (2003) 46:1284-1290]

Keywords PAI-1, obesity, metabolic syndrome, CHD, fasting glucose, insulin, triglycerides, HDL, Type 2 diabetes mellitus.
The metabolic insulin resistance syndrome associates a cluster of risk factors for Coronary Arterial Disease (CAD), including hyperinsulinaemia, Impaired Glu-

Received: 3 March 2003 / Revised: 7 April 2003

Published online: 11 July 2003

C Springer-Verlag 2003

Corresponding author: Dr. P. Froguel, CNRS 8090-Institute of Biology, Institut Pasteur de Lille, 1 Rue du Professeur Calmette, B.P. 447, 59021 Lille, France

E-mail: froguel@mail-good.pasteur-lille.fr

Abbreviations: PAI-1, Plasminogen activator-inhibitor 1; SNP, single nucleotide polymorphism; T2D, Type 2 diabetes. cose Tolerance (IGT) or chronic hyperglycaemia (Type 2 diabetes, T2D), central obesity, and complex dyslipidaemia with hypertriglyceridaemia and hypoHDL-cholesterolaemia [1, 2]. In addition, a decreased fibrinolytic capacity has been shown to contribute to the high prevalence of Coronary Heart Disease (CHD) in individuals and cohorts with metabolic syndrome $[3,4]$, for which CHD has been generally attributed to increased type 1 plasminogen activator inhibitor (PAI1) activity.

PAI-1, a member of the serine protease inhibitor (SERPIN) family, is a main regulator of the endogenous fibrinolytic system. It inhibits fibrinolysis activity of the 
tissue-type plasminogen activator, tPA, which produces active plasmin from plasminogen, that then cleaves fibrin [5]. Thus, PAI-1 determines in part fibrinolysis activity and modulates the progression of thrombosis [6, 7]. PAI- 1 is expressed and secreted in a variety of tissues, including liver, spleen [8] and adipocytes [9]. PAI1 synthesis is regulated by various agents, including insulin [10], very-low-density lipoprotein, VLDL [11], low-density lipoprotein and glucose [12].

The human PAI-1 gene is located at chromosome $7 q 22[13]$ in a region that shows a linkage with lipid concentrations in Mexican Americans [14, 15]. Moreover, it has been shown that PAI-1 activity correlates with features of the insulin resistance syndrome [6], in particular, plasma insulin and triglyceride concentrations in subjects with CHD [16], T2D [17, 18] and obesity $[19,20]$. Interestingly, obese and diabetic ob/ob mice deprived of the PAI-1 gene showed reduced adiposity [21].

In light of these data, PAI- 1 is a good candidate gene and that might contribute to the pathological features associated to the metabolic syndrome. To verify this role of PAI-1, we have screened the promoter and coding sequence of PAI-1 gene and identified five potentially functional polymorphisms: two known promoter polymorphisms, the $-7654 \mathrm{G} / 5 \mathrm{G}$ and the -844 $A>G$, and three previously unknown non-synonymous single nucleotide polymorphisms (SNPs). We genotyped these five polymorphisms in a case-control cohort to determine if an association is present between PAI-1 genotypes and metabolic parameters linked to diabetes and obesity. Possible functional effects of these variants were also analyzed.

\section{Methods}

Subjects. A case-control cohort of 1067 unrelated French Caucasians was stratified for diabetic status, fulfilling the 1999 WHO criteria for diabetes mellitus (Diabetic/normoglycaemic subjects $675 / 391$; mean age $63.6 \pm 11.6 / 62.6 \pm 10.3$ years; mean BMI $28.0 \pm 5.8 / 32.9 \pm 11.0 \mathrm{~kg} / \mathrm{m}^{2}$; sex ratio Male to Female 378-297/132-259) and for obesity, defined as BMI greater than or equal to 30 (Obese/non obese subjects 343/690; mean age $62.6 \pm 9.5 / 63.7 \pm 11.8$ years; mean BMI $39.9 \pm 6.1 /$ $24.6 \pm 2.9 \mathrm{~kg} / \mathrm{m}^{2}$; sex ration Male to Female 110-233/381-308). In this cohort, biochemical variables were measured in the fasting state. Glycaemia (mmol/l), triglyceridaemia, total- and HDL-cholesterolaemia ( $\mathrm{mmol} / \mathrm{l})$ were measured enzymatically (Roche, Boehringer, Meylan, France) and insulinaemia (mU/l) was measured immunologically (IRMA, Immunotech, BioRadPasteur IRMA, France). Coronary Heart Disease (CHD), diagnosed by physicians, was defined as presence of myocardial infarction, angina pectoris, bypass or the presence of a pathological Q wave on a current electrocardiogram. Informed consent was given by each participant. The protocol has been approved by the Hotel Dieu ethical Committee.

Screening and genotyping PAI-1 polymorphisms. DNA was extracted from EDTA whole-blood samples using the Puregene kit (Gentre, Minneapolis, Minn., USA).
We scanned $1 \mathrm{~kb}$ of the $P A I-1$ promoter and the entire coding sequence $(1.2 \mathrm{~Kb})$ for SNPs by direct sequencing in 48 randomly selected unrelated Type 2 diabetic French Caucasian subjects. The protocol was carried out using a 3700 DNA sequencer (Applied Biosystems, Foster City, Calif., USA) as previously described [22].

Identified polymorphisms of the PAI-1 gene were genotyped using LightCycler technology (Roche, Manheim, Germany) based on hybridization probes labelled with fluorescent dyes. Polymorphisms were identified by differences of fluorescence resonance energy transfer (FRET) during melting curve analysis [23].

Statistical analysis. In order to use parametric methods, skewness of quantitative trait distributions were normalized by $\log _{\mathrm{e}}$ transformation. Chi-square tests were used to analyze deviation of the genotype frequency from the distribution that would be expected if alleles were in Hardy-Weinberg equilibrium and to test differences in genotype frequencies between groups. Log-normalized quantitative variables were compared using the ANOVA tests and, when positive, with the non parametric rank, Wilcoxon and Kruskal-Wallis tests. Calculations were carried out using SSPS 10.0 program (SSPS, Chicago, Ill., USA). In each test, a $p$ value of less than 0.05 was considered statistically significant. Haplotype frequencies and standardized linkage disequilibrium (D') were determined with the $\mathrm{PM}+\mathrm{EH}+$ software.

\section{Results}

Genetic screening of the promoter and coding sequences of PAI-1 gene in a French Caucasian cohort resulted in the identification of five variants. Of them, Ala15Thr, Val17Ile and Asn195Ile, were previously uncharacterized and are non synonymous polymorphisms. The Ala15Thr and Val17Ile are both determined by substitution of a guanine to adenine in exon 2 , and lead to a change of alanine to threonine at position 15 , and of valine to isoleucine at position 17 , respectively. The Asn195Ile, an asparagine to isoleucine change at position 195 , is determined by an adenine to thymine substitution in exon 4 (Table 1).

The two other variants, both in the promoter, were the common single-base-pair guanine deletion/insertion, $4 \mathrm{G} / 5 \mathrm{G}$, at $-675[24,25]$ and the SNP $-844 A>G$ [26]. The two known promoter polymorphisms showed similar frequencies as previously reported in other Caucasian populations $[24,26]$.

All the polymorphisms were in Hardy-Weinberg equilibrium (Table 1), except the $-844 A>G$ variant which differed significantly $\left(\chi^{2}=5.49, p=0.02\right)$, as was previously described [26].

The Val17Ile and Asn195Ile variants (Table 1) were rare (14 heterozygous subjects for Val17Ile and 1 heterozygous individual for Asn195Ile, among 532 genotyped subjects). Due to their very low frequencies, genetic statistical analyses for these SNPs were not relevant. The other three, $-6754 \mathrm{G} / 5 \mathrm{G},-844 A>G$ and Ala15Thr, showed a very high linkage disequilibrium, with a standardized linkage disequilibrium $\left(\mathrm{D}^{\prime}\right)$ for each polymorphism pair: $-6754 \mathrm{G} / 5 \mathrm{G} /-844 A>G$, 
Table 1. Genotypic and allelic frequencies for the five variants of PAI-1 gene. $n=1067$ for $4 \mathrm{G} / 5 \mathrm{G},-844 \mathrm{~A}>\mathrm{G}$ and Ala15Thr variants; $n=532$ for Val17Ile and Asn195Ile variants. For each variant, the most frequent allele is indicated first. For the three non-synonymous polymorphisms, the corresponding codon sequences were indicated in brackets. Significance of $\chi^{2}$ to test discordance from the Hardy-Weinberg equilibrium was indicated (HWE)

\begin{tabular}{|c|c|c|c|c|c|c|}
\hline \multirow{2}{*}{$\frac{\text { Polymorphisms }}{4 \mathrm{G} 5 \mathrm{G}}$} & \multicolumn{3}{|c|}{ Genotypes } & \multicolumn{2}{|c|}{ Alleles } & \multirow{2}{*}{$\begin{array}{l}\text { HWE } \\
\text { ns }\end{array}$} \\
\hline & $\begin{array}{l}4 \mathrm{G} 4 \mathrm{G} \\
0.27\end{array}$ & $\begin{array}{l}4 \mathrm{G} 5 \mathrm{G} \\
0.52\end{array}$ & $\begin{array}{l}5 \mathrm{G} 5 \mathrm{G} \\
0.21\end{array}$ & $\begin{array}{l}4 \mathrm{G} \\
0.53\end{array}$ & $\begin{array}{l}5 \mathrm{G} \\
0.47\end{array}$ & \\
\hline$-844 \mathrm{~A}>\mathrm{G}$ & $\begin{array}{l}\text { AA } \\
0.33\end{array}$ & $\begin{array}{l}\mathrm{AG} \\
0.52\end{array}$ & $\begin{array}{l}\text { GG } \\
0.15\end{array}$ & $\begin{array}{l}\text { A } \\
0.59\end{array}$ & $\begin{array}{l}\mathrm{G} \\
0.41\end{array}$ & 0.02 \\
\hline Ala15Thr (GCC $>$ ACC $)$ & $\begin{array}{l}\text { GG } \\
0.80\end{array}$ & $\begin{array}{l}\text { GA } \\
0.19\end{array}$ & $\begin{array}{l}\text { AA } \\
0.01\end{array}$ & $\begin{array}{l}\mathrm{G} \\
0.90\end{array}$ & $\begin{array}{l}\text { A } \\
0.10\end{array}$ & $\mathrm{~ns}$ \\
\hline Val17Ile (GTC $>$ ATC) & $\begin{array}{l}\text { GG } \\
0.97\end{array}$ & $\begin{array}{l}\text { GA } \\
0.03\end{array}$ & $\begin{array}{l}\text { AA } \\
0.00\end{array}$ & $\begin{array}{l}\mathrm{G} \\
0.99\end{array}$ & $\begin{array}{l}\mathrm{A} \\
0.01\end{array}$ & $\mathrm{~ns}$ \\
\hline Asn195Ile (AAC $>$ ATC) & $\begin{array}{l}\text { AA } \\
0.998\end{array}$ & $\begin{array}{l}\text { AT } \\
0.002\end{array}$ & $\begin{array}{l}\text { TT } \\
0.00\end{array}$ & $\begin{array}{l}\text { A } \\
0.999\end{array}$ & $\begin{array}{l}\mathrm{T} \\
0.001\end{array}$ & ns \\
\hline
\end{tabular}

Table 2. Association analysis for glucose metabolism parameters in non-diabetic subjects. Means \pm standard deviation of glycaemia and insulin in non-diabetic obese (Fat, $n=173$ ) and non-obese (Lean, $n=141$ ) individuals. ANOVA tests were used with $\log _{\mathrm{e}}$-normalized values. Significant differences were observed between homozygous individuals for more frequent alleles of the two promoter variants and individuals carrying the less frequent variants, following a dominant genetic model

\begin{tabular}{lllccl}
\hline & SNP & Population & Genotype 11 & $12+22$ & $p$ value \\
\hline Glycaemia (mmol/l) & 4G5G & Lean & $5.1 \pm 0.5$ & $5.12 \pm 0.4$ & 0.9 \\
& & Fat & $5.5 \pm 0.4$ & $5.3 \pm 0.4$ & 0.006 \\
& $-844 \mathrm{~A}>\mathrm{G}$ & Lean & $5.1 \pm 0.5$ & $5.12 \pm 0.4$ & 0.9 \\
& & Fat & $5.5 \pm 0.4$ & $5.2 \pm 0.4$ & 0.0004 \\
& Ala15Thr & Lean & $5.1 \pm 0.4$ & $5.1 \pm 0.5$ & 0.6 \\
& & Fat & $5.3 \pm 0.4$ & $5.3 \pm 0.5$ & 0.9 \\
Insulin $(\mathrm{mU} / \mathrm{l})$ & Lean & $6.7 \pm 3.4$ & $8.1 \pm 5.4$ & 0.8 \\
& & Fat & $13.5 \pm 9$ & $10.8 \pm 5.7$ & 0.05 \\
& & Lean & $6.4 \pm 3.8$ & $8.2 \pm 5.4$ & 0.2 \\
& & Fat & $13.6 \pm 8.3$ & $10.5 \pm 5.7$ & 0.008 \\
& & Lean & $7.8 \pm 5.1$ & $7.9 \pm 5.6$ & 0.8 \\
& Ala15Thr & & $11.9 \pm 7.2$ & $10 . \pm 5.3$ & 0.3 \\
\hline
\end{tabular}

$\mathrm{D}^{\prime}=0.9772 ;-675$ 4G/5G/Ala15Thr, $\mathrm{D}^{\prime}=0.9997 ;-844$ $A>G /$ Ala15Thr, $\mathrm{D}^{\prime}=0.9207$.

Genotypic and allelic frequencies of the three variants did not significantly differ between T2D and nondiabetic individuals (data not shown).

Chi-square tests with obesity and analysis of variance of BMI with regard to the $-844 A>G$ polymorphism showed an increased obesity of non-diabetic homozygous $A A$ subjects (Obese/Lean AA: 0.36/0.26, $p=0.04$; BMI: $34.7 \pm 11.4 / 31.8 \pm 10.9, p=0.02$ ). A similar, although not significant trend was observed for -675 $4 \mathrm{G} / 5 \mathrm{G}$ polymorphism in non-diabetic subjects homozygous for the $4 \mathrm{G}$ allele (4G4G) (Obese/Lean 4G4G: 0.29/0.21, $p=0.06$; BMI: $34.5 \pm 11.0 / 32.2 \pm 11.0, p=0.08$ ).

Given the possible association between PAI-1 and BMI analysis of variance of glucose and lipid metabolism associated traits were carried out in obese and lean individuals without therapy (non-diabetic or nonhyperlipidaemic subjects) (Table 2; Table 3). Differences were observed in fasting glycaemia and insulinaemia in non-diabetic obese individuals for the two promoter variants (Table 2). Homozygotes for the most frequent alleles ( $4 \mathrm{G}$ and $A$ alleles for $4 \mathrm{G} / 5 \mathrm{G}$ and $-844 A>G$ polymorphisms, respectively) showed highly increased levels of fasting glucose and insulin (glycaemia: $p=0.006$ and $p=0.0004$, for $4 \mathrm{G} / 5 \mathrm{G}$ and $-844 A>G$ polymorphisms, respectively; insulinaemia: $p=0.05$ and $p=0.008$, for $4 \mathrm{G} / 5 \mathrm{G}$ and $-844 A>G$ polymorphisms, respectively), which might suggest an increased insulin-resistance in these carriers. In contrast, the Ala15Thr variant did not show association with these parameters (Table 2).

To analyze lipid profiles, we selected individuals without lipid-lowering therapy. A decreased level of triglycerides $(p=0.09, p=0.0027$ and $p=0.09$, for $4 \mathrm{G} / 5 \mathrm{G},-844 A>G$ and Ala15Thr polymorphisms, respectively) and an increased level of $\operatorname{HDL}(p=0.27$, $p=0.027$ and $p=0.01$, for $4 \mathrm{G} / 5 \mathrm{G},-844 A>G$ and Ala15Thr polymorphisms, respectively) were observed in lean individuals homozygous for the most frequent alleles (Table 3), while no significant associations were observed in obese individuals. 
Table 3. Association analysis for lipid metabolism parameters. Means \pm standard deviation of triglyceride and HDL cholesterol in non-obese individuals ( $n=485 ; 355$ diabetic and 130 nondiabetic subjects). Significant or indicative differences were

\begin{tabular}{|c|c|c|c|c|}
\hline Trait & SNP & Genotype 11 & $12+22$ & $p$ value \\
\hline Triglyceride (mmol/l) & $\begin{array}{l}\text { 4G5G } \\
-844 \mathrm{~A}>\mathrm{G} \\
\text { Ala15Thr }\end{array}$ & $\begin{array}{l}1.29 \pm 0.9 \\
1.24 \pm 0.8 \\
1.33 \pm 0.8\end{array}$ & $\begin{array}{l}1.39 \pm 0.9 \\
1.43 \pm 0.9 \\
1.55 \pm 1.1\end{array}$ & $\begin{array}{l}0.09 \\
0.0027 \\
0.09\end{array}$ \\
\hline HDL (mmol/l) & $\begin{array}{l}\text { 4G5G } \\
-844 \mathrm{~A}>\mathrm{G} \\
\text { Ala15Thr }\end{array}$ & $\begin{array}{l}1.49 \pm 0.4 \\
1.53 \pm 0.5 \\
1.48 \pm 0.4\end{array}$ & $\begin{array}{l}1.45 \pm 0.4 \\
1.43 \pm 0.4 \\
1.37 \pm 0.4\end{array}$ & $\begin{array}{l}0.27 \\
0.027 \\
0.01\end{array}$ \\
\hline
\end{tabular}

observed for triglyceride and HDL cholesterol, between homozygous individuals for more frequent alleles of the variants and individuals carrying the less frequent variants, following a dominant genetic model
Table 4. Association analysis for coronary complication in diabetes. Genotype and allelic frequencies in diabetic individuals with (CHD; $n=229)$ and without (NoCHD; $n=406)$ coronary complications. Significant or indicative differences were shown for the three variants

\begin{tabular}{lllllll}
\hline Polymorphisms & Genotypes & & $p$ value & Alleles & & $p$ value \\
\hline 4G5G & $4 \mathrm{G} 4 \mathrm{G}$ & $4 \mathrm{G} 5 \mathrm{G}+5 \mathrm{G} 5 \mathrm{G}$ & & $4 \mathrm{G}$ & $5 \mathrm{G}$ & \\
CHD & 0.31 & 0.69 & & 0.56 & 0.44 & \\
NoCHD & 0.26 & 0.75 & 0.1 & 0.51 & 0.49 & 0.05 \\
-844 A $>$ G & $\mathrm{AA}$ & $\mathrm{AG}+\mathrm{GG}$ & & $\mathrm{A}$ & $\mathrm{G}$ & OR=1.31 [1.04-1.65] \\
CHD & 0.38 & 0.62 & 0.63 & & 0.37 & \\
NoCHD & 0.32 & 0.68 & 0.13 & 0.57 & 0.43 & 0.02 \\
Ala15Thr & $\mathrm{GG}$ & GA+AA & & $\mathrm{G}$ & $\mathrm{A}$ & OR $=1.48[1.02-2.16]$ \\
CHD & 0.83 & 0.17 & 0.02 & 0.91 & 0.09 & \\
NoCHD & 0.76 & 0.24 & & 0.88 & 0.12 & 0.04 \\
\hline
\end{tabular}

Of the 675 T2D subjects studied, 229 had a clinical history of coronary heart disease (CHD). The allelic frequency for the three polymorphisms differed between the two groups (Table 4), with and without CHD: the diabetic group with CHD had a higher frequency of carrier of the most frequent alleles $[4 \mathrm{G} / 5 \mathrm{G}$ : $p=0.05 ; \quad-844 A>G: \quad \mathrm{OR}=1.31 \quad(1.04-1.65), \quad p=0.02$; Ala15Thr: OR=1.48 (1.02-2.16), $p=0.04]$. Attributable risk for CHD due to the presence of the risk alleles for $-844 A>G$ and Ala15Thr polymorphisms was estimated at $15 \%$ and $30 \%$, respectively.

Haplotype analyses were carried out for the three common polymorphisms in regard to diabetic status, obesity and coronary complications. Differences between haplotype frequencies in T2D individuals with or without coronary complications were observed for $-844 A>G$ and the Ala15Thr polymorphisms (A-Ala: 0.625/0.563; A-Thr: 0.002/0.007; G-Ala: 0.291/0.318; G-Thr: 0.082/0.112; $p=0.029$, for CHD/non CHD diabetic patients respectively). The CHD at risk haplotype was determined by the two most frequent alleles (haplotype A-Ala).

Phenotypes of the 14 subjects carrying the rare Val17Ile variant were analyzed and compared to the remaining population, but no differences were observed (data not shown).

The Asn195Ile variant was identified in only one diabetic individual. The genotypes of other members of this family were determined and analyzed for co-
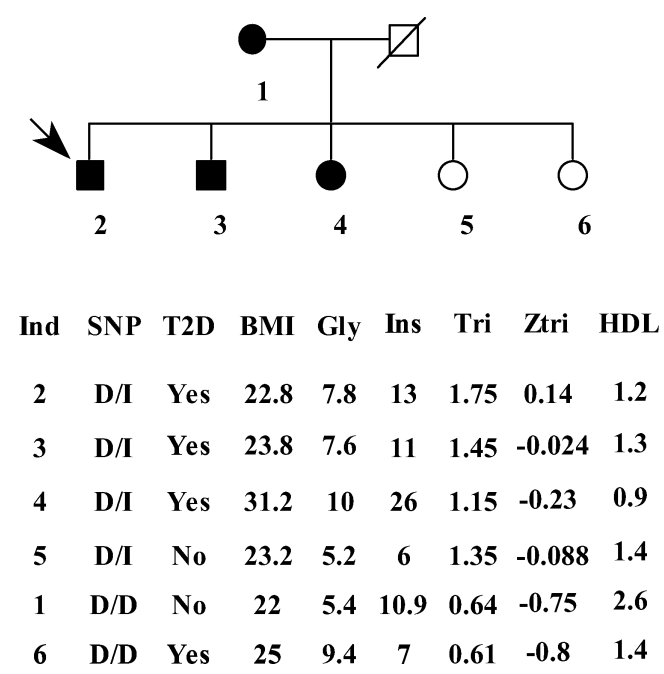

Fig. 1. Co-segregation analysis for the N195I polymorphism of PAI-1. In genealogical tree, diabetic subjects are indicated in black. Individual 2, pointed by arrow, was included in the diabetic cohort. The father was not analyzed, and his phenotypes are unknown. For each individual (1-6), genotype was indicated (N or I amino acid), diabetic status (T2D), BMI, fasting glucose (Gly) and insulin (Ins), triglyceride (Tri) and corresponding standardized value, Z score (Ztri) and HDL cholesterols

segregation with diabetes and quantitative traits (Fig. 1). Carriers of the rare allele showed higher concentrations of triglycerides compared to the other members. When expressed in standard deviation 
unites (Z-score), we observed a difference of 0.8 standard deviation units.

The potential effects of these new non-synonymous SNPs on PAI-1 protein conformation were predicted using algorithms available at ProtScale (http://www. expasy.org/cgi-bin/protscale.pl) (data not shown).

The Ala15Thr and the Val17Ile are located in the signal peptide consisting of the first 23 amino acids of PAI-1 [27]. The alanine to threonine change in position 15 could result in a lower propensity to form $\alpha$-helix [28] and in decreased hydrophobicity [29]. In contrast, no effects of the Val 17 to Ile 17 change were observed on these two parameters. The Asn195Ile SNP is part of a $\beta$-sheet structure (184-195 AA) and the rare allele Ile 195 might result in a higher $\beta$-sheet propensity [28] and in increased hydrophobicity [29].

\section{Discussion}

In addition to the two already reported polymorphisms in the promoter sequence of PAI-1, we have identified three missense mutations in the coding region. Only the Ala15Thr missense mutation, located in the signal peptide, was prevalent enough (10\%) to allow association studies in our population. This variant and the two promoter mutations are in high but not in full LD with each other, they were not associated with T2D. However, our data indicated that the two promoter polymorphisms were associated with obesity and could modulate BMI in non-diabetic subjects. Moreover, presence of the most frequent alleles of these polymorphisms is associated with a more severe insulin-resistant profile in obese subjects, who have higher fasting glucose, insulin and triglyceride, and lower HDL cholesterol than non-carrier obese subjects. Moreover, the most frequent alleles for PAI-1 polymorphisms also conferred a higher risk for CHD in diabetic individuals, a population known to be already at risk for premature atherosclerosis.

Unexpectedly, in healthy non-obese middle-aged subjects, the PAI- 1 most frequent alleles seemed to be associated with lower triglyceride and higher HDL cholesterol concentrations, suggesting that these alleles might be "protective" for metabolic cardiovascular risk in the absence of fat excess. A similar dual effect was already reported for the angiotensin converting enzyme gene (ACE), for which the deletion (D) allele was more frequently found in subjects with myocardial infarction [30, 31], but was also more prevalent in centenarians [32] and in elite athletes in power-oriented performances [33,34]. Given the role of PAI-1 in the control of fibrinolysis, it could be an advantage to have relatively increased PAI-1 levels at a certain age, if not associated with potent metabolic disturbances.

We have studied three polymorphisms for association with three-disease status (T2D, Obesity and
CHD) and five quantitative traits (BMI, fasting glucose, insulin, triglycerides and HDL cholesterol). Using Bonferroni correction, a global $p$ value of 0.05 , will be represented by a $p$ value of at least 0.0021 in one single test. Under this condition, only the association between the $-844 A>G$ polymorphism and the fasting glycaemia in obese non-diabetic subjects was significant. However, there was a strong LD between the 3 PAI-1 polymorphisms and a strong correlation between fasting glucose and diabetes $\left(\mathrm{R}_{\text {Spearman }}=\right.$ $-0.74, p<0.0001)$ and between BMI and obesity $\left(\mathrm{R}_{\text {Spearman }}=-0.82, p<0.0001\right)$, and between triglycerides and HDL cholesterol $\left(\mathrm{R}_{\text {Pearson }}=-0.39, p<0.0001\right)$. Therefore, a less conservative correction could be applied (one variant block and five phenotypes, uncorrected $p=0.01$ ). Accordingly, we have associations between the two promoter variants and higher levels of fasting glucose and between the $-844 A>G$ SNP and higher levels of insulin, in obese non-diabetic subjects, and between this SNP and lower levels of triglycerides in lean untreated subjects. Nevertheless, future studies are needed to replicate our results in other populations.

Previous studies suggested an association between PAI-1 $-844 A>G$ and the $4 \mathrm{G} / 5 \mathrm{G}$ polymorphisms and vascular complications in non-insulin-dependent diabetic individuals [35, 36]. Moreover, fasting insulin levels, triglycerides and BMI have also been associated with the $4 \mathrm{G} / 5 \mathrm{G}$ in subjects with hyperlipidaemia and premature coronary disease or non-insulin-dependent diabetes in Caucasians [24, 37, 38], but not in all tested populations $[39,40]$. Recently, an association was found for the $4 \mathrm{G} / 5 \mathrm{G}$ variant with obesity in a Scandinavian population [41], but these results were not further confirmed $[42,43]$. These findings together with our data illustrate the difficulty to analyze genotype-phenotype correlation in complex traits whereby environmental factors strongly modulate the possible effects of gene polymorphisms on human diseases.

Importantly, the $-6754 \mathrm{G} / 5 \mathrm{G}$ has been found to correlate with higher plasma PAI-1 activity in patients with myocardial infarction [24, 25] and in subjects with deep vein thrombosis [26]. In contrast, another study failed to show any effect of the $-844 A>G$ SNP on plasma PAI-1 level [26]. Expression studies showed that the $-6754 \mathrm{G} / 5 \mathrm{G}$ polymorphism affects the binding of nuclear proteins regulating PAI- 1 transcription $[24,25]$. Although both alleles bind a transcriptional activator, the $5 \mathrm{G}$ allele also binds a repressor protein to an overlapping binding site, increasing the basal level of PAI-1 gene transcription [24, 25]. Furthermore, the -844 SNP that is part of an Ets nuclear protein consensus sequence binding site could also be implicated in the regulation of the PAI- 1 gene $[26,42]$.

The other three identified SNPs are responsible for amino acid changes and could interfere with PAI- 1 activity. In particular, the Ala15Thr SNP, which is asso- 
ciated with CHD in diabetic individuals, is located in the central hydrophobic core of the PAI-1 signal peptide. The most frequent risk allele of this SNP increases hydrophobicity and $\alpha$-helix propensity, indicating that it could stabilize the $\alpha$-helix conformation of the signal peptide. These two properties are known to be important in signal peptide function and therefore the mutations might modulate the secreted PAI-1 level. In this regard, a similar amino acid change has been shown to be a functional mutation, interfering with the translocation to the membrane of the thyrotropin receptor [44].

Interestingly, we also identified a PAI-1 non-synonymous SNP, Asn195Ile that seemed to co-segregate with a higher level of triglyceride in a single pedigree. This SNP, included in a $\beta$-sheet structure, caused alteration of hydrophobicity and $\beta$-sheet propensity, where the rare allele could promote a more stable conformation.

Our results support the hypothesis that PAI-1 polymorphisms contribute to increased body fat in nondiabetic subjects. PAI-1 SNPs probably interact with known environmental risk factors (chronic hyperglycaemia, obesity, etc.) to induce a more severe insulin-resistant metabolic profile in overweight subjects, and to further increase the risk for CHD in diabetic subjects.

It is not yet clear whether the association between PAI-1 activity and overweight- and obesity-associated metabolic traits is directly due to PAI-1 action or it is only a consequence of the increased body fat that secretes excess PAI-1. A reduced adiposity has been observed in obese and diabetic $o b / o b$ mice that are also deprived of the PAI-1 gene [21], suggesting a primitive effect of PAI-1 on adiposity. Our results are in agreement with this hypothesis, as potential functional PAI-1 SNPs modulate obesity-associated phenotypes in human.

Acknowledgements. This work was supported by a grant from E. Lilly though Lilly Consortium for Diabetes and Obesity (M. McCarty, P. Froguel, R. Leibel, M. Lathrop, J. Caro and E. Ravussin). We thank B. Neve and M. Rachidi for critical reading of the manuscript.

\section{References}

1. Reaven GM (1988) Role of insulin resistance in human disease. Diabetes 37:1595-1607

2. DeFronzo RA, Ferrannini E (1991) Insulin resistance. A multifaceted syndrome responsible for niddm, obesity, hypertension, dyslipidemia, and atherosclerotic cardiovascular disease. Diabetes Care 14:173-194

3. Juhan-Vague I, Thompson SG, Jespersen J (1993) Involvement of the hemostatic system in the insulin resistance syndrome. A study of 1500 patients with angina pectoris. The ECAT angina pectoris study group. Arterioscler Thromb 13:1865-1873

4. Hamsten A, Faire U de, Walldius G et al. (1987) Plasminogen activator inhibitor in plasma: Risk factor for recurrent myocardial infarction. Lancet 2:3-9
5. Kruithof EK, Tran-Thang C, Ransijn A, Bachmann F (1984) Demonstration of a fast-acting inhibitor of plasminogen activators in human plasma. Blood 64:907-913

6. Juhan-Vague I, Alessi MC (1997) PAI-1, obesity, insulin resistance and risk of cardiovascular events. Thromb Haemost 78:656-660

7. Alessi MC, Peiretti F, Morange P, Henry M, Nalbone G, Juhan-Vague I (1997) Production of plasminogen activator inhibitor 1 by human adipose tissue: Possible link between visceral fat accumulation and vascular disease. Diabetes 46:860-867

8. Loskutoff DJ, Samad F (1998) The adipocyte and hemostatic balance in obesity: Studies of PAI-1. Arterioscler Thromb Vasc Biol 18:1-6

9. Shimomura I, Funahashi T, Takahashi M et al. (1996) Enhanced expression of PAI-1 in visceral fat: Possible contributor to vascular disease in obesity. Nat Med 2:800-803

10. Alessi MC, Juhan-Vague I, Kooistra T, Declerck PJ, Collen D (1988) Insulin stimulates the synthesis of plasminogen activator inhibitor 1 by the human hepatocellular cell line Hep G2. Thromb Haemost 60:491-494

11. Stiko-Rahm A, Wiman B, Hamsten A, Nilsson J (1990) Secretion of plasminogen activator inhibitor-1 from cultured human umbilical vein endothelial cells is induced by very low density lipoprotein. Arteriosclerosis 10:1067-1073

12. Nordt TK, Klassen KJ, Schneider DJ, Sobel BE (1993) Augmentation of synthesis of plasminogen activator inhibitor type- 1 in arterial endothelial cells by glucose and its implications for local fibrinolysis. Arterioscler Thromb 13:1822-1828

13. Klinger KW, Winqvist R, Riccio A et al. (1987) Plasminogen activator inhibitor type 1 gene is located at region q21.3-q22 of chromosome 7 and genetically linked with cystic fibrosis. Proc Natl Acad Sci USA 84:8548-8552

14. Arya R, Blangero J, Williams K et al. (2002) Factors of insulin resistance syndrome-related phenotypes are linked to genetic locations on chromosomes 6 and 7 in nondiabetic mexican-americans. Diabetes 51:841-847

15. Duggirala R, Blangero J, Almasy L et al. (2000) A major susceptibility locus influencing plasma triglyceride concentrations is located on chromosome $15 \mathrm{q}$ in mexican americans. Am J Hum Genet 66:1237-1245

16. Landin K, Tengborn L, Smith U (1990) Elevated fibrinogen and plasminogen activator inhibitor (PAI-1) in hypertension are related to metabolic risk factors for cardiovascular disease. J Intern Med 227:273-278

17. Juhan-Vague I, Roul C, Alessi MC, Ardissone JP, Heim M, Vague P (1989) Increased plasminogen activator inhibitor activity in non insulin dependent diabetic patients-relationship with plasma insulin. Thromb Haemost 61:370-373

18. Potter van Loon BJ, Kluft C, Radder JK, Blankenstein MA, Meinders AE (1993) The cardiovascular risk factor plasminogen activator inhibitor type 1 is related to insulin resistance. Metabolism 42:945-949

19. Vague P, Juhan-Vague I, Aillaud MF et al. (1986) Correlation between blood fibrinolytic activity, plasminogen activator inhibitor level, plasma insulin level, and relative body weight in normal and obese subjects. Metabolism 35:250-253

20. Landin K, Stigendal L, Eriksson E et al. (1990) Abdominal obesity is associated with an impaired fibrinolytic activity and elevated plasminogen activator inhibitor-1. Metabolism 39:1044-1048

21. Schafer K, Fujisawa K, Konstantinides S, Loskutoff DJ (2001) Disruption of the plasminogen activator inhibitor 1 gene reduces the adiposity and improves the metabolic profile of genetically obese and diabetic ob/ob mice. FASEB J 15:1840-1842 
22. Boutin P, Wahl C, Samson C, Vasseur F, Laget F, Froguel P (2000) Big dye terminator cycle sequencing chemistry: accuracy of the dilution process and application for screening mutations in the TCF1 and GCK genes. Hum Mutat 15:201-203

23. Blomeke B, Sieben S, Spotter D, Landt O, Merk HF (1999) Identification of $\mathrm{N}$-acetyltransferase 2 genotypes by continuous monitoring of fluorogenic hybridization probes. Anal Biochem 275:93-97

24. Dawson SJ, Wiman B, Hamsten A, Green F, Humphries S, Henney AM (1993) The two allele sequences of a common polymorphism in the promoter of the plasminogen activator inhibitor-1 (PAI-1) gene respond differently to interleukin-1 in HepG2 cells. J Biol Chem 268:10739-10745

25. Eriksson P, Kallin B, van 't Hooft FM, Bavenholm P, Hamsten A (1995) Allele-specific increase in basal transcription of the plasminogen- activator inhibitor 1 gene is associated with myocardial infarction. Proc Natl Acad Sci USA 92:1851-1855

26. Grubic N, Stegnar M, Peternel P, Kaider A, Binder BR (1996) A novel $\mathrm{g} / \mathrm{a}$ and the $4 \mathrm{~g} / 5 \mathrm{~g}$ polymorphism within the promoter of the plasminogen activator inhibitor-1 gene in patients with deep vein thrombosis. Thromb Res 84:431-443

27. Pannekoek H, Veerman H, Lambers Het al. (1986) Endothelial plasminogen activator inhibitor (PAI): a new member of the serpin gene family. EMBO J 5:2539-2544

28. Deleage G, Roux B (1987) An algorithm for protein secondary structure prediction based on class prediction. Protein Eng 1:289-294

29. Kyte J, Doolittle RF (1982) A simple method for displaying the hydropathic character of a protein. J Mol Biol 157:105-132

30. Cambien F, Poirier O, Lecerf L et al. (1992) Deletion polymorphism in the gene for angiotensin-converting enzyme is a potent risk factor for myocardial infarction. Nature 359:641-644

31. Tiret L, Kee F, Poirier O et al. (1993) Deletion polymorphism in angiotensin-converting enzyme gene associated with parental history of myocardial infarction. Lancet 341:991-992

32. Schachter F, Faure-Delanef L, Guenot F et al. (1994) Genetic associations with human longevity at the APOE and ACE loci. Nat Genet 6:29-32

33. Woods D, Hickman M, Jamshidi Y et al. (2001) Elite swimmers and the D allele of the ACE I/D polymorphism. Hum Genet 108:230-232

34. Nazarov IB, Woods DR, Montgomery HE et al. (2001) The angiotensin converting enzyme I/D polymorphism in russian athletes. Eur J Hum Genet 9:797-801
35. Mansfield MW, Stickland MH, Grant PJ (1995) Plasminogen activator inhibitor-1 (PAI-1) promoter polymorphism and coronary artery disease in non-insulin-dependent diabetes. Thromb Haemost 74:1032-1034

36. Nagi DK, McCormack LJ, Mohamed-Ali V, Yudkin JS, Knowler WC, Grant PJ (1997) Diabetic retinopathy, promoter (4 g/5 g) polymorphism of PAI-1 gene, and PAI-1 activity in Pima indians with type 2 diabetes. Diabetes Care 20:1304-1309

37. Panahloo A, Mohamed-Ali V, Lane A, Green F, Humphries SE, Yudkin JS (1995) Determinants of plasminogen activator inhibitor 1 activity in treated NIDDM and its relation to a polymorphism in the plasminogen activator inhibitor 1 gene. Diabetes 44:37-42

38. Mansfield MW, Stickland MH, Grant PJ (1995) Environmental and genetic factors in relation to elevated circulating levels of plasminogen activator inhibitor- 1 in caucasian patients with non-insulin-dependent diabetes mellitus. Thromb Haemost 74:842-847

39. McCormack LJ, Nagi DK, Stickland MH et al. (1996) Promoter $(4 \mathrm{~g} / 5 \mathrm{~g})$ plasminogen activator inhibitor-1 genotype in Pima indians: Relationship to plasminogen activator inhibitor-1 levels and features of the insulin resistance syndrome. Diabetologia 39:1512-1518

40. Viitanen L, Pihlajamaki J, Halonen P et al. (2001) Association of angiotensin converting enzyme and plasminogen activator inhibitor-1 promoter gene polymorphisms with features of the insulin resistance syndrome in patients with premature coronary heart disease. Atherosclerosis 157:5764

41. Hoffstedt J, Andersson IL, Persson L, Isaksson B, Arner P (2002) The common $-6754 \mathrm{~g} / 5 \mathrm{~g}$ polymorphism in the plasminogen activator inhibitor -1 gene is strongly associated with obesity. Diabetologia 45:584-587

42. Henry M, Chomiki N, Scarabin PY et al. (1997) Five frequent polymorphisms of the PAI-1 gene: Lack of association between genotypes, PAI activity, and triglyceride levels in a healthy population. Arterioscler Thromb Vasc Biol 17:851-858

43. Freeman MS, Mansfield MW (2002) Comment to: J. Hoffstedt et al. (2002) the common $-6754 \mathrm{~g} / 5 \mathrm{~g}$ polymorphism in the plasminogen activator inhbitor-1 gene is strongly associated with obesity. Diabetologia 45:1602-1603

44. Abramowicz MJ, Duprez L, Parma J, Vassart G, Heinrichs C (1997) Familial congenital hypothyroidism due to inactivating mutation of the thyrotropin receptor causing profound hypoplasia of the thyroid gland. J Clin Invest 99:30183024 